\title{
Crossing International and Research Boundaries: From Subject to Author for an Authentic Refugee Portrait
}

\author{
Jasenka Besic ${ }^{1}$ and J. Lynn McBrien ${ }^{2}$ \\ ${ }^{1}$ College of Education, University of Georgia, Athens, GA 30602, USA \\ ${ }^{2}$ College of Education, University of South Florida, 8350 N. Tamiami Trail, B322, Sarasota, FL 34243, USA
}

Correspondence should be addressed to J. Lynn McBrien, jlmcbrien@sar.usf.edu

Received 28 December 2011; Accepted 1 February 2012

Academic Editors: F. Jimenez, M. Reis, and B. J. Walton Moss

Copyright (C) 2012 J. Besic and J. L. McBrien. This is an open access article distributed under the Creative Commons Attribution License, which permits unrestricted use, distribution, and reproduction in any medium, provided the original work is properly cited.

\begin{abstract}
Scholars in training, including qualitative researchers, are often cautioned about their relationship to their research participants with the notion that "getting too close" can distort findings. However, with many participants, especially those with whom issues of trust are problematic due to their personal experiences, researchers cannot gain rich data without creating an authentic and close relationship. In this longitudinal study, a female Bosnian youth and an academic researcher grapple with issues of trust, friendship, and research in an effort to determine ways to create valid research findings over years of relationship building.
\end{abstract}

\section{Introduction}

Because of the complex relationships of the two authors of this research, which will be made apparent in the paper, most of this study does not use the collective "we" but frequently separates into two distinct voices. Voice is especially important to this work, as I, [McBrien], began researching and working with refugee youth while a graduate student ten years ago, so I am only able to report the words of the refugees and reflect on their meaning. Besic, however, is a 22-year-old refugee from Bosnia who has been both a subject of the work and a coauthor in the last phases of the project. Thus, hers is an authentic voice in describing and analyzing the refugee experience. For clarity, when using "I" in this paper, we will parenthetically note the writer as the author changes. At times, this style is awkward, but we felt it essential to write with distinctive voices as we offer narrations and critiques of ourselves and each other.

Ten years ago, I [McBrien] walked into a noisy building that was formerly a store, transformed by five-foot high gray partitions into tutoring spaces for refugee students in Grades One through Eight by an independent refugee agency we will call "Help for Refugee Families" (HRF). As part of my doctoral work in a Comparative Education course, I volunteered 15 hours to help the students with their homework. Very quickly, my obligation became my rather complicated passion, as I have had to constantly grapple with my role as both a researcher of and an advocate for refugee students. As I begin my eleventh year of research with refugee students resettled in the United States, primarily in the Southeast, I have had to ask myself "Should ongoing relationships with young refugees prevent or somehow discredit my ability to include them in my research?".

The question is especially important in regards to writing about several students that I met back in 2002 and have followed as they progressed from middle or high school into college. I tutored several of the girls and worked as their summer camp counselor at the refugee agency. I chose to follow these young women because my initial work with them revealed remarkable success in spite of tragic refugee backgrounds and ongoing discrimination in the United States [1]. I have written recommendations for some of the girls' college and scholarship applications. I nominated my coauthor for national and state awards and scholarships, most of which she has received. I have taken the students out for dinner to celebrate graduations. We email each other and share digital photos of family and events. They have invited me to graduations, family dinners, wedding showers, and their Facebook pages. After I left the area to take a position in Florida, one of the young women emailed me "How is 
the teaching going? I hope your students are inspired by you because I am. I miss you so much. When are you going to visit? I hope soon."

Clearly, I have been an influence in their lives. This is hardly the picture of a detached researcher gathering data for journal articles, and it seems to go beyond the typical scope of reciprocity for which most qualitative researchers strive. As a result, one of the purposes of this paper is to grapple with methods and ethical issues that can occur in longitudinal qualitative research.

One of my goals as a researcher is to argue that refugees must be studied apart from other groups of immigrants [1-3]. They are forced to leave their homelands for fear of persecution, torture, or death, and they often have no time to plan their departure or to necessarily know to where they will travel. (We use the UNHCR's definition of refugees: "people who are outside their country and cannot return owing to a well-founded fear of persecution because of their race, religion, nationality, political opinion or membership of a particular social group" (UNHCR, 2006, ๆ 8)) Their life contexts are typically filled with multiple traumas ranging from physical assaults (anything from warinflicted to disease) to the psychological trauma of leaving homes, being separated from family members, and watching family or friends be raped, tortured, or killed [4]. The mother of one of the participants in my studies had one of her hands amputated prior to becoming a refugee. Another spent nine years as a refugee in Iran then Pakistan; once in a tent in a cemetery, at other times in a one-room apartment with her family before arriving in the United States. Though her family was forced to flee because of Hussein's attacks on Kurds, she was often taunted by US peers with the words "Hussein's daughter" and "terrorist."

These contextual details are important information for researchers as well as teachers and providers of social services. Persecution and fear cause many refugees to be wary of authorities [5,6]. Many refugee children suffer from posttraumatic stress disorder [7, 8]. People working with refugees must realize that the students may take time to trust them and not push the students to reveal aspects of their lives that can cause them to relive traumatic events [9]. However, my work has not concentrated on a deficit model. In contrast, refugee youth with whom I have worked have provided leads to support that result in success [1].

My first research study with refugees was a qualitative study with 18 adolescent refugee girls [1]. I have stayed in close contact with four of them. Initially, I determined to stay in touch with several of the original participants because I wanted to know how their lives would progress and how their experiences with US schools and higher education would play a role in their adult lives. Through the years of contact, however, I have also gained varying degrees of what I would call "friendship" with each of these young women. All four progressed to become university students. Two have reached successes beyond what most native US students hope to achieve (one of whom is the coauthor of this paper). One graduated pre-med after obtaining a four-year scholarship and an internship at the Center for Disease Control (CDC); she is currently working in a research position at a top-tier private university. For personal reasons, she has chosen not to be a part of this longitudinal study.

I [Besic] completed my undergraduate degree at a private university in Georgia, and my master's degree at The University of Georgia (UGA). I currently teach kindergarten at an expeditionary learning school in Georgia. I have also applied to begin my doctorate at UGA while looping to first grade with my students. McBrien has written several recommendations for me to receive a scholarship towards this degree. I received a national award for exemplary community service from the Hitachi Foundation, a state award for service, and several scholarships. It is my hope that writing with Lynn will explore and confront perspective in the work. The key questions in our research have been the following: "What can create enduring resilience in the lives of young refugee women, and to what can they attribute their high rates of success?" Additionally, in this study, we grapple with the researcher-participant relationship.

Obviously, the portrait of one remarkably successful young refugee woman cannot be generalized. What it can do, however, is explore the kinds of support that can allow someone who has undergone years of trauma, fear, and discrimination to rise above discrimination and become highly successful. Our study also addresses the kind of researcherparticipant relationship that allows for a deep, personal exploration of the self in addressing these questions; the accuracy an outsider may hope to attain in telling the other's story; the precariousness of crossing research borders that we were taught to maintain in graduate school methods courses.

1.1. A Refugee Perspective. I [Besic] first met McBrien (I called her "Ms. Lynn") as my summer camp counselor at the HRF refugee agency. I was actually very excited to meet her. It was my first time attending this summer camp, and, at the time I met her, my English vocabulary was still expanding. My confidence level was low, even though I had been in the United States for four years. I had to get accustomed to a new society, language, culture, school, and friends. It was a huge transition in my life, and, by far, the most difficult time I have gone through in life so far. Ms. Lynn was one of the few adults I had come across who was actually understanding and patient with me. Usually, this was not the case. I had often felt invisible and pushed to one side of the room. She would bring interesting topics to camp, in which I would be deeply interested, and I was able to learn new vocabulary from them. Our discussions were open, and everyone had a chance to speak.

At the end of summer camp, Ms. Lynn made each camper in our group a beautiful "memory calendar" filled with pictures of our summer experiences. I still have it today and every single time I look at it, it brings a smile to my face. We have stayed in touch throughout the years. Ms. Lynn has definitely supported me throughout the years, much more than I expected. I could not believe that she took the time to fill out an extremely long nomination form for the Hitachi Foundation national award for exemplary service to the community. I was on the selection committee last year and saw how long and how far in depth the nomination materials were. Not only that, but Ms. Lynn 
came as my guest to the award ceremony in Washington DC.

My first reaction to working on this project was that it was going to be a new experience and I could learn so much from it, but something I deeply considered was the fact that I would be a research subject. Why should I decide to share my life, stories, struggles, ambitions, lowest moments, and dreams with others? On the other hand, I think it is helpful for others to understand my pains and struggles. Being involved allows me to share my perspective, and I deeply value the opportunity to actually raise my voice on behalf of other refugee students who have come to the United States. I see this as an excellent opportunity to help others understand students like me. I have learned throughout life as well as reading Adam Smith that people do not go through the same struggles, but similar struggles. The way we can relate is by opening our eyes to different perspectives.

\section{Methods: Portrait Presentation and Contexts}

Numerous qualitative researchers have struggled with the relationship between researcher and informants. Reflecting on sociolinguistic methods used in the Ocracoke community of North Carolina, Wolfram [10] described reciprocity as "social, educational, and economic alliances" (272). Although Wolfram stated that the research team was always construed as language researchers, he also commented that the researchers' roles included friendship. Recognizing sometimes problematic issues of power and authority that arose in the research, Wolfram referred to Cameron and colleagues' [11] "advocacy research" framework of "ethics, advocacy, and empowerment" ([10, page 272]). Though Wolfram stated that most sociolinguists would not oppose creating "collaborative relationships" that could benefit the researched community, he noted that the details of such collaborations could be "complicated and controversial" (page 273).

Giltin [12] and de Carteret [13] described their own struggles with traditional hierarchies of research methods in their attempts to be inclusive, authentic, and honest. Both researchers discussed the use of alternative methodspoetics, journaling, storytelling, and imagination-as ways of transcending authoritarian forms of research. For Gitlin, a nontraditional approach involved nonconformity and "the freedom...to act on the world" (page 635). He stated that by challenging the assumptions of accepted forms of research methods, "[academics] are involved in the risky business of shunning the advantages of being part of the research club, with its link to the establishment of the title Expert" (page 641). But adherence to the standards of the "club" causes the researcher to lose the freedom of perspectives that may provide needed insight. I [McBrien] recognize that in my own work combining research and advocacy, the conservative stance of "objectivity" is compromised. However, the unorthodox approach creates potential for greater public awareness and acceptance of resettled refugees, as well as an opportunity to gain a deeper understanding.

For de Carteret [13], the journey into nontraditional qualitative work involved the need to recognize her place in the research, signified by her dissertation supervisor's question, "Where are you in all of this?" (page 238). She described her formal research proposal as "disembodied objectivity" (page 238), and her process for alternative research practices brought her to allow both for vulnerability and "ethical practices of empathy" (page 239). Vulnerability allows the researcher to be more open to the voice of the research subject in learning not what is expected, but what may be unexpected.

Finally, Lawrence-Lightfoot and Davis [14] offer a path through the dilemma of personal relationships to participants with the method of portraiture. Lawrence-Lightfoot and Davis began their book with an explanation of the main tenets of the method, which include a search for what is "good and healthy" (page 9) as opposed to the traditional deficit model; a voice for the subjects of the study; an attempt to not only inform, but also inspire; the necessity of context; the inevitability of intervention. "In the process of creating portraits, we enter people's lives, build relationships, engage in discourse, make an imprint..." (page 11). As a result, the researcher is also faced with "ethical dilemmas and a great moral responsibility" (page 11). How can the researcher portray the lives of the subjects without getting in the way? How accurate is the work? Would similar results occur if the researcher had not been present in the lives of her subjects? Answers to such questions can only be conjecture. A key to portraiture work is to continually note the presence and the subjectivity of the researcher. As such, I [McBrien] view myself as a subject in the study along with the inspiring young women who have taught me about what it means to be a resettled refugee in the United States.

Davis [14] used a tale by Nicolaides, an artist and teacher, who imagined a man from Mars observing a landscape on Earth for the first time. Nicolaides reflected on how a drawing by the Martian would be different than a drawing of the same scene by a human because the Martian would be relating the objects in the scene to what he knew on Mars. Nicolaides concluded that the two artists' results would only be comprehensible, one to the other, at interconnections of similar experience. Davis related the story to portraiture.

\begin{abstract}
The image of the man from Mars (the outsider) portraying objects with which he has little or no familiarity is analogous to the situation in which the portraitist is forging relationships with individuals (insiders) whose experiences and environment may be entirely different from her own. How will the portrayal be intelligible if the experiential base of the portraitist does not include prior knowledge of the realities of the subject or actors on a site? (page 176)
\end{abstract}

Not only must the portrait be intelligible; it must be authentic, valid. Miles and Huberman [15] suggest increasing validity by engaging participants in the work. Researchers can ask them to read interview transcripts and conclusions in order to learn if the researcher's data analysis reflects the participants' experiences and beliefs accurately.

Through emails, we decided to take a further step towards authenticity by examining and critiquing together the early 
years of data collection by McBrien with final current writing and reflection by Besic. This approach also increases the portraitist's element of "empathetic regard": what LawrenceLightfoot and Davis [14] stated develops through asking the question "if I were looking at the world through her eyes, what would I see?" (page 146) This study offers the ability to see through the eyes of a participant and through her understanding of the refugee experience. Data included eight years of interview transcripts and Besic's current reflections on her experiences.

The findings section begins with portraits of Besic: an historical one drawn by McBrien (and critiqued by Besic), and a reflective, contemporary one drawn by Besic (with a response by McBrien). Following these historical backgrounds, we proceed to examine ways in which McBrien, as the outsider, has been accurate and inaccurate in explaining Besic's success and supports.

2.1. McBrien's Portrait of Besic. As Besic has written, I [McBrien] first met her when I worked as a summer camp counselor at HRF in 2003. I worked with the oldest group of adolescent girls, Grades 7-9. I viewed Jasenka as an enthusiastic, friendly girl who quickly became a leader among her peers. Thus, it was surprising to me to read Besic's paragraph describing herself with low confidence and to read that she perceived me as one of few adults who was understanding and patient with her. I would not have expected this to be the case. She always had suggestions for free time games, dialogues, music, and videos. However, unlike her peers, Besic did not seem interested in listening to or memorizing lyrics to current rap and hip-hop songs, nor did she try to emulate the sexual dance moves on which many of the girls were fixated. She did, however, suggest a role play based on the Ricky Lake Show for our summer-end variety show, and she starred as the "valley girl" who lamented the tom-boy clothes and behaviors of her peers.

As an activity at summer camp, the students were asked to draw self-portraits. I recall being fascinated by Besic's (Figure 1). The face is a rainbow of colors surrounded by a thick, dark layer of hair, then a layer of pink. To me, that suggested that there were many layers of feelings, or experiences, that were hidden in her mind.

Jasenka Besic was born in Doboj, Bosnia, in October 1988. At the time she turned 4, war erupted between Christians and Muslims in the region. Her father was drafted into the army, and Jasenka and her mother fled to Germany. She told me that because her father was Muslim, he was not retained in the army. He was able to rejoin the family in Germany nine months later.

Besic told me about waiting with her mother at the border of Hungary and Germany. They did not have money to pay the border patrolman, so he was unwilling to let them pass through. After many hours, he allowed them to go, Besic observed, probably because he noticed "how pitiful we looked having shed so many tears.” Jasenka recalls that Germany was a mixture of positive and painful experiences. She was shy due to her accent and need to learn German. She also said that foreigners could not own a home or hold a good job that was not physically labor intensive. On the positive

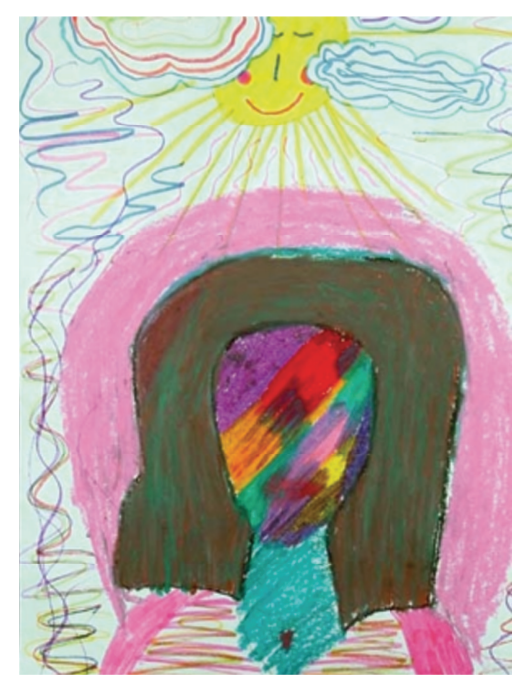

FIGURE 1: 2003 self-portrait by A1.

side, she recalls feeling safe and learning the importance of family.

Besic said that her family received notice they had to leave Germany in 1998. They could return to Bosnia, still torn apart by war, or move to the United States. And she said "I had to leave my friends, teddy bears, and books once again."

Beyond the trauma of leaving Bosnia at the advent of civil war, Besic's next significant trauma occurred in her fourth grade classroom in the US. There were six other Bosnian students in the class with whom the teacher assumed Besic should associate. However, Jasenka was the child of a Muslim father and an orthodox Christian mother, neither of whom were particularly religious. The other Bosnian students in the class were conservative Muslims, and when they learned of Besic's religious background, according to her, they "tormented her." She also felt they were not as driven as she to advance in school, and her progress caused them to hurt her all the more. She said "they drew pictures of burned crosses, used profane language I had never heard of, and blamed me for the Bosnian war. All those months of anguish, my teacher did not notice a thing." Besic's mother recognized her anguish and was finally able to get a meeting with the teacher, counselor, and Bosnian students. However, Jasenka still feels the impact of the discrimination; she said "that meeting supposedly healed my wounded heart, but to this day I am scarred. I am unable to speak about this openly because of how much it still hurts me." She could not discuss it without tears.

When I interviewed Jasenka's mother, she told me about extreme depression she endured when the family moved to the United States. HRF became a place of hope for her as she took English language lessons there. Eventually, she was employed at the agency, and she became the director of the Special Service project, a program for those youth who are at very high-risk due to circumstances such as teen pregnancy, involvement with crime, or violent living situations. She was frequently overcome with emotion when she talked to me about difficult experiences of refugee clients or of her daughter's painful experiences. Jasenka told me that she was 
initially embarrassed by both her and her parents' inabilities with the English language. But she is now proud of her parents, because she recognizes all they have endured to provide her and her younger sister with a promising future.

When I interviewed Besic in 2006 during her senior year in high school, I asked her about the factors in her life that she believed supported her throughout her flight from Bosnia, years in Germany, and final resettlement in the United States. Her immediate response was the strength she drew from her mother.

My mother is persistent, strong. She is the main person who helped me be so successful today. Most refugee children do not have that; they're also trying to find what to do. My mom and I were always close. I can talk to her about everything.

She also commented that her family, in general, was a source of strength. Jasenka noticed differences between her own families and US families.

Being refugees taught us to stick together. Family is all you have. It helped us in everything. In the US, I notice family is not as close. Children are free to do whatever they want especially when they turn eighteen. My parents taught me family is always going to be with you even if everything and everyone else leaves. Best friends may leave you. People I've known all my life would have never done what my family did for me, especially my mother.

Besic specifically stated that negative experiences, failures, and encounters with discrimination, rather than becoming a reason to give up, actually worked as motivating factors in her life. She recounted an incident in sixth grade in which she failed a test. Another student, who received an A, laughed at her. She said, "someone trying to bring me down got me up." Besic was also motivated when she saw other students who were doing poorly in school. She explained

I see something going on like too many kids failing a class, and nobody's doing anything about it. I believe every child is capable of making it, and why not help them? My motivation is if they aren't doing well, why should I not help? Why should I just watch idly from the sidelines?

While she volunteered at HRF, Besic was motivated to help refugee children who did not have the family support she valued. She spoke of one young Liberian girl who came to the center dressed in poorly fitting, dirty clothes, and who had behavioral problems. Jasenka told me that the girl had been abandoned by her mother and was living in an abusive situation. Through intervention with HRF and Child Services, the child was placed in a caring home. Besic recalled seeing the girl again, after the situation was corrected:

I saw her this year and got so emotional because of this child. I couldn't understand why a child should go through that. I'm sitting there, she comes in looking at me, and I think, Is that who I think it is? Oh my gosh, it's her! I jump off the table and run, hug her, tears in our eyes, happy to see the success. She could remember I had helped her.

The final motivator Besic mentioned in the 2006 interview was the agency HRF itself. She saw both the help the agency gave to her and her family, as well as the experiences she had subsequently as a volunteer, as a motivation in her success and her life goals. At the time, she wanted to become an elementary teacher-and perhaps a dentist.

RFS made a huge impact-everything about my life since I was a student there has grown so much. It helped me decide on my career. I want to be an elementary school teacher, if not double major in dentistry and education. I want to go as high as possible to make my own academy. There is a way every child can learn, no matter what where they come from, what system they come from. As for dentistry, countries that are war-torn they do not have resources. Why should not I help them?

At the time of this writing, Besic is a kindergarten teacher at an expeditionary learning school in Georgia who anticipates beginning her doctoral studies in 2012. She continues with many volunteer activities. She has applied for a Soros New American Scholarship, for which I have written a recommendation.

2.2. Besic's Response and Self-Portrait. It was interesting to read that McBrien perceived me as "as an enthusiastic, friendly girl who quickly became a leader among her peers." It was extremely difficult for me to find my identity at that point when I met her at summer camp. I was in a new world with different views, customs, language, and mentality. Everything was happening so fast. I did not have real friends like I did in Germany, the language barrier was enormous, and I truly felt that nobody understood me. At the summer camp, I was around students with similar backgrounds as me, but they chose to conform to the traditional "American" way of life. At the time, I was different from other children because I had the parental support that many other refugee youth lack to this day for many different reasons. The parents usually work different shifts, taking on more than one job to make sure there is food on the table, and being extremely tired at the end of the day. There is no way that they have the kind of money it takes to hire a nanny or send their children to an after-school program. Even though the HRF after-school program is free, children need transportation, and that prevents some from attending.

When I first started fourth grade in this new country with a different system, new language, and a completely different culture, I had a difficult time finding my identity and friends. The language barrier was painful because people were not able to understand me and I was not able to understand them. Many times, I felt hopeless, but there was always 
a curiosity in me that wanted to learn this new language, make new friends, and learn about other cultures, even though I had to leave mine behind.

A moment of happiness came over me when I was introduced to six Bosnian students in my classroom. Finally, I had people who could understand one of the languages I spoke. Unfortunately, that happiness did not last long. This group immediately wanted to find out more about me; my name was not enough. They wanted to find out more about me in this sense: Which religious group did I belong to? Did I cause the war? Was I the reason they had to leave their country? What were my parents' names? What was my last name? These five girls and one boy ended up finding out my mother's name and started teasing me about it. I had no idea why they would tease me over my mother's name or a religion. My parents did not force religion or certain beliefs on me. I had no idea what they were referring to. All I knew was that all those hateful words they used against me every day hurt me. I would go home and sit in my room, crying. I did not want to go to school and I stopped being happy.

One day, they drew a picture and told me that I was going to burn in Hell because I was not Muslim. It had many curse words on it with a picture of a cross burning and crossed out. My parents happened to come from two different religious backgrounds. How was I the cause of the war? Why were they blaming me? I was just an innocent child, unaware of why my family had to start our lives over for the second time. My mom kept asking what was wrong, but I was too hurt to say something. Luckily, my mom is a persistent individual, and she went to my school to find out what was going on. A meeting was scheduled, and all of the Bosnian students were there. They were told that their actions were not allowed, and that was the end of it, but nothing could heal my wounded heart at that time. My teacher had been unaware of the issues, because she assumed that all Bosnians would stick together. That would be reasonable, except that the war was between three different religious groups.

McBrien referred to the self-portrait I drew in summer camp (Figure 1). As I look at this picture I drew years ago, I cannot help but think about my sense of self at that time. It was not developed, neither was it close to developing. I was in the middle stage of finding out who I was, what I stood for, and what I believed in. I was at a very critical stage in my life, and I felt that I had a difficult time fitting in with a particular group. Cliques were incredibly important to teenagers to feel like they belonged. I really did not belong to a particular group, and I was scrutinized for it by peers. Luckily, I had a support system (my family) that would not allow me to become depressed due to peers' opinions. The picture represented that I was like a chameleon and could be friends with all kinds of people. I was not just set to a particular way of thinking. I remember that I was thinking of the amount of times we moved-first from Bosnia and then from Germany when I colored my hair and the layers in between. My face stood for confusion and the desire to belong. The sun stood there shining down on me with its eyes closed because I wasn't happy at that point, but I've overcome that.

I am happy that I can reflect on this picture today and have completely different feelings about it. Today, this picture
I drew of myself stands for all the changes I went through in my life. I have grown to become a mature individual with a strong sense of self and identity. I know who I am, I know what I stand for, I know what I believe in, and I know who I am. The sun is my motivation, smiling down on me letting me know that I will get there-reaching my goals and fulfilling all my dreams.

In all honesty, it is awkward having someone else tell my story and it is vital that my history is told from my perspective. It is awkward in the sense that someone would attempt to understand my story. Most people when they hear it, they just say "I am so sorry," with pity for me. I do not believe that this should be the answer. It is a sad story, even though I have eventually attained much success, but I do not want to feel sorry for myself, my family, other refugees/immigrants, or for other people to feel sorry for me. The war happened and cannot be undone, so the next step is to prevent it from happening to others-human rights are important and should be valued across our globe. Prevention is key instead of sitting by idly. Each individual has a story, but at the end all that a human being really wants and strives for is respect, not pity. I want someone to be my friend not because they feel sorry for me, but because they see my personality, my heart. That is what is important in my eyes.

People with limited access to power, to media, have to make sure to entrust the right people to tell their stories just the way they happened. I do not think that someone else could have told my story better. The reason I placed trust in McBrien is because she took the time to listen to every detail, with questions, especially thought-provoking questions. I learned in one of my leadership courses at my undergraduate institution that it is critical that we choose the right people to retell our history. There was a time that there was a skewed version of my story. I had won a national award (one that McBrien nominated me for), and my school wanted to do a press release. I was originally at a different meeting, but a person in authority asked me to go into the publishing manager's office, even though I told her I had a class in ten minutes. She insisted I sit down and speak with her. She asked a few questions like "Why did you get this award?" and "When did you come to the U.S.?" Basically, it was a short version of my life story. The point was to make a press release about the national recognition I received, but she kept wanting to talk about my personal story and life. I did not see that it would benefit her press release.

The story was filled with fluff, exaggerating facts that the writer did not know. She asked what other things I had been doing, and I shared that I was a part of a public service announcement project, yet the press release said that I mentioned a slogan in a P.S.A. I felt used this time. I felt like this because the reporter spent so little time, did not give me a draft to look over, did not ask me any questions via email at the very least, and decided to publish it. My voice was not heard in that press release. I felt like the only reason this was published was because my school happened to have a refugee from Bosnia that received a national award to get the school media attention.

At the beginning of high school, I was in regular classes. I had a counselor just like everyone else. On top of that I was 
a peer leader, so working closely with my counselor. That means that this counselor should have gotten to know me well. Instead of challenging me with more difficult courses, my counselor kept telling me I should go to the local community college. What if I did not want to go there? I asked her about that, but not once did she mention AP classes or honors classes until my algebra teacher recommended I take honors courses. He saw my potential, while she did not. I was able to read her recommendation letter, which is required to be written by one's counselor. It stated that I was an immigrant. That part alone showed how much she had gotten to know me: none. I actually ran into her recently, and she did not have words once she heard that I had completed my Master's degree. Many refugees work so hard to succeed in their new homes because they care about their lives and are grateful for the chance to begin again, but many people remain ignorant to these facts.

Today, my life is good. I do not have any complaints. I do not have to live with fear of being persecuted, a fear of practicing or choosing a religion, or having to leave my home. I am extremely grateful that I attend a good school. My parents have jobs, we are all healthy, we have a place called home, and, most importantly, we have each other.

I live in the land of opportunity where every dream is possible. In this regard, it is not as difficult as it seems to "pull oneself up by their bootstraps." I do not even have to think twice about things because I can attain them. Once I set a goal, I am determined to reach it.

My life is stable. There have been many changes that have taken place since September 21st, 1998. I can travel back to Germany and Bosnia to remind myself of all those memories. I actually plan on visiting Germany this summer, after summer school. This will be the first time in 10 years that I will see old neighbors, my old street, school, path that I took to school every single day, and other childhood memories that I am looking forward to.

I am proud of the person that I have become. I have done a lot of self-growth throughout the years. I have achieved this self-growth being raised by strong parents. I am extremely proud of my parents. They are my heroes because they have not only overcome great adversity but have also built a safe life for their family. They have adapted to this new society, customs, mentality, and way the US system works.

The incredible amount of support I have had from my mother is most important, and I am forever thankful to her.

I have had a difficult time understanding people who have lived in the United States all their lives. I always wondered why the homeless exist in such a flourishing country filled with opportunities. Why cannot they pull themselves up with the help of all the support services available? Today, I understand that every individual is different and has a different thinking process and mentality. I know that services are lacking in many areas, people lose their jobs in a country that they trust, and that life is filled with unexpected events. The key to building a successful social structure within the US is a truly equal educational approach starting in Pre-K and Head Start programs.

My hopes for the future are to influence policy on the local, state, and federal levels, helping children that do not have their voices heard. I want to make sure our system caters to every kind of child. Whether the child has a disability, language barrier, or home problem they should have a supportive educational environment in which they will succeed.

\section{Discussion}

Jasenka sent me a clip from a local television show that covered an award she received. In it, she again referred to the United States as "the land of opportunity." Resilience and hope theories refer to success as contextualized and relational [16]. In Besic's words are found both the contextualization of the United States as a country in which to prosper and grow; and positive outgrowth of relationships with family, HRE, and her research relationship, as both subject and author, with McBrien.

As a critic of many United States' policies, especially political actions since the $9 / 11$ attacks, I cannot imagine calling the country the "land of opportunity where every dream is possible," even though I recognize my advanced safety and freedom in comparison to millions of people living in more repressed nations. However, it is important that I acknowledge Besic's perception of the country and ways in which that perception may have contributed to her personal success. In attempting to understand people's perceptions of life, their successes, and failures, I am reminded of the landmark play by Pirandello: Così è (Se Vi Pare), It is so! (If You Think So) (1917/1922), in which characters' beliefs create their realities based on their beliefs. As a middle-class White woman born in the United States, I have enjoyed unearned advantages throughout my life that have also allowed me the luxury of criticizing US policies that I find politically or socially problematic. However, I also traveled to Bosnia in 2007, and I have seen the remaining physical and psychological effects of the war and heard about ongoing tensions from citizens of Sarajevo. Besic also returned to Bosnia in 2006, and she described her contrasting views concerning opportunities in the United States versus few opportunities for education and careers in Bosnia. The stark contrast and lived reality of Besic contribute to her perspective that she can achieve whatever she chooses in the United States, similarly to the tale of the "man from Mars" described by Davis ([14, page 176]).

Besic's narrative surely offers not only information, but also inspiration that Lawrence-Lightfoot [14] suggested can surface through portraiture. Here is a young woman who has been singled out as a successful youth in the United States, in spite of her traumatic childhood years as a refugee. Clearly her portrait opposes the traditional deficit model, and it offers suggestions for increasing success, in terms of supportive community institutions as well as family. It also suggests a role for research that extends beyond the traditional model to one of advocacy. Indeed, it supports the contentions of feminist researchers Bhavnani, Foran, and Kurian [17], who asserted that women from the developing world are not universally victims as can be suggested by Western scholarship. Rather, they suggested that these women confront challenge in creative, effective ways, and their struggles can evoke a strong sense of agency. 
Throughout my role in this longitudinal research, I [McBrien] have been aware of my position of power. As the author who is a professor at a research university, I have knowledge of literature, of scholarly methods, and access to publishing that Besic did not have prior to her higher education experiences. I questioned my telling of Jasenka's story, even though it was told largely from taped interviews with her. Always in working with refugee participants, I have been aware of an unequal power differential that could potentially affect responses I would receive from refugee informants.

Nominating Besic for national and community awards that she won gave her a public voice beyond the confines of a scholarly paper. She received media publicity for both of these awards, and she was inspired to take a leadership role in the Run for Darfur. Her local leadership in that project resulted in an invitation to be a spokesperson at the national rally in Washington, DC. As I was completing edits on this paper she sent me an audio email of a national public service announcement for radio that she narrated about one of her many accomplishments through volunteerism.

Of course, it is not possible to determine causation between these various events and relationships. As I have come to know Jasenka, I believe she is fully capable of having reached all of these accomplishments without my intervention. However, my decision to nominate her for awards, which she ultimately received, had the effect of giving Jasenka more of a public voice to speak out on behalf of resettled refugees in the United States, a voice that I contend is much needed.

As for my own role as a researcher in the area of resettled refugees, I could not have learned about the emotional pain encountered by Besic and her family without the trust she gave to me as a result of our long-term relationship that I would term a mentoring relationship and a kind of friendship. I consider this knowledge critical to my understanding as a researcher. At the same time, were she to have determined that this information was too private to disclose to a public audience, of course, I would defer to her preference.

What are the lessons of this longitudinal study? As we have reflected on our work and our research/personal relationships, we have noted several major themes that are of importance to the greater community of researchers and those who work with refugees and other immigrants. First are our differing perceptions of success and selfconfidence. My perceptions of Besic's sense of self were quite different from hers. Besic presented a confident self to me, and this accomplished self has resulted in many accolades for her. However, she often did not feel self-assured, and she intimated her insecurities and fears. Mosselson's [18] research also exposes self-assured masks of adolescent refugee Bosnian girls. In the case of her research, these girls intentionally chose a persona of success in order to avoid being singled out for remedial help of any kind. In either case, it is important for professionals to note that an external persona may cloak important needs.

I [Besic] call for understanding and respect, not pity. Pity is more of a mechanism for the dominant group to feel good about itself, whereas the more important and difficult work of understanding and respect involves recognition of the "other" as someone who is equally capable of achievement, who deserves an equal voice. This insight relates to my discussion of the news reporter-and a school—that had a preconceived agenda in creating a story about a successful refugee student.

The school counselor had low expectations of my abilities. Given my progress and awards, this counselor's expectations were below my capabilities. It may be that the counselor had too great a load of students to get to know me; thus she relied, perhaps unconsciously, on stereotypes, and may, in fact, have believed that she was offering me advanced educational opportunities by suggesting community college. Given that so few refugee students have the external supports of a strong family presence and a community organization to support refugee students, it is critical to educate school counselors and administrators about the resilience and academic capability of many refugee students so that they do not reduce opportunities for these students. Ultimately, their successes become successes for the country.

There is an irony between my [McBrien] criticism of my country and Besic's and the optimism of other entrants' optimism, who are often oppressed by US residents. Many refugees and other immigrants choose to come to the United States because they have heard of unsurpassed opportunities and freedoms offered by this country. Indeed, these newcomers, with their hopeful visions of the United States, may be the strongest vision of progress for the country. Both Jasenka's work and ambitions, along with work I have conducted with other refugee youth [1], indicate not only an attitude, but also targeted work towards a more caring, equitable world. Yet this vision is not simplistic. In considering Besic's initial confusion about US disparities, she comes to recognize that the concept of a meritocracy is hardly reality in the United States, as all citizens do not approach life on an equal playing field. We concur that it is education that can offer to reduce the disparities, but not without significant post-training opportunities for staff and teachers that can help them to understand better the capacities inherent in refugee and other immigrant students.

\section{References}

[1] J. L. McBrien, "Beyond survival: school-related experiences of adolescent refugee girls and their relationship to motivation and academic success," in Global Issues in Education: Pedagogy, Policy, School Practices and the Minority Experience, G. Wiggan and C. Hutchinson, Eds., pp. 294-330, Roman \& Littlefield, 2009.

[2] J. L. McBrien, "Serving the needs of at-risk refugee youth: a program evaluation," Journal of School Public Relations, vol. 27, pp. 326-341, 2006.

[3] J. L. McBrien, "Educational needs and barriers for refugee students in the United States: a review of the literature," Review of Educational Research, vol. 75, no. 3, pp. 329-364, 2005.

[4] K. Frater-Mathieson, "Refugee trauma, loss, and grief: implications for intervention," in Educational Interventions for Refugee Children: Theoretical Perspectives and Implementing Best Practice, R. Hamilton and D. Moore, Eds., pp. 12-34, Routledge Falmer, London, UK, 2004. 
[5] J. Boyden, "Conducting research with war-affected and displaced children: ethics and methods," Cultural Survival Quarterly, vol. 24, no. 2, pp. 70-73, 2000.

[6] T. Hynes, "The issue of "trust" or "mistrust" in research with refugees: choices, caveats and considerations for researchers," in New Issues in Refugee Research, Working Paper 98, UNHCR, Geneva, Switzerland, 2003.

[7] S. Goldin, B. Hägglöf, L. Levin, and L. Å. Persson, "Mental health of Bosnian refugee children: a comparison of clinician appraisal with parent, child and teacher reports," Nordic Journal of Psychiatry, vol. 62, no. 3, pp. 204-216, 2008.

[8] B. Vickers, "Cognitive model of the maintenance and treatment of post-traumatic stress disorder applied to children and adolescents," Clinical Child Psychology and Psychiatry, vol. 10, no. 2, pp. 217-234, 2005.

[9] C. Igoa, The Inner World of the Immigrant Child, Lawrence Erlbaum Associates, Mahwah, NJ, USA, 1995.

[10] W. Wolfram, "Scrutinizing linguistic gravity: issues from the field," Journal of Sociolinguistics, vol. 2, no. 2, pp. 271-279, 1998.

[11] D. Cameron, E. Frazer, P. Harvey, M. B. Rampton, and K. Richardson, Researching Language: Issues of Power and Method, Routledge, London, UK, 1992.

[12] A. Gitlin, "Cultivating the qualitative research borderlands: educational poetics and the politics of inclusivity," International Journal of Qualitative Studies in Education, vol. 21, no. 6, pp. 627-645, 2008.

[13] P. de Carteret, "Storytelling as research praxis, and conversations that enabled it to emerge," International Journal of Qualitative Studies in Education, vol. 21, no. 3, pp. 235-249, 2008.

[14] S. Lawrence-Lightfoot and J. H. Davis, The Art and Science of Portraiture, Jossey-Bass, San Francisco, Calif, USA, 1997.

[15] M. B. Miles and A. M. Huberman, Qualitative Data Analysis: An Expanded Sourcebook, Sage, Thousand Oaks, Calif, USA, 2nd edition, 1994.

[16] S. C. Yohani, "Creating an ecology of hope: arts-based interventions with refugee children," Child and Adolescent Social Work Journal, vol. 25, no. 4, pp. 309-323, 2008.

[17] K. Bhavnani, J. Foran, and P. A. Kurian, "An introduction to women, culture, and development," in Feminist Futures: ReImaging Women, Culture, and Development, K. Bhavnani, J. Foran, and P. Kurian, Eds., pp. 1-21, Zed Books, London, UK, 2003.

[18] J. Mosselson, "Masks of achievement: an experiential study of Bosnian female refugees in New York City schools," Comparative Education Review, vol. 51, no. 1, pp. 95-115, 2007. 

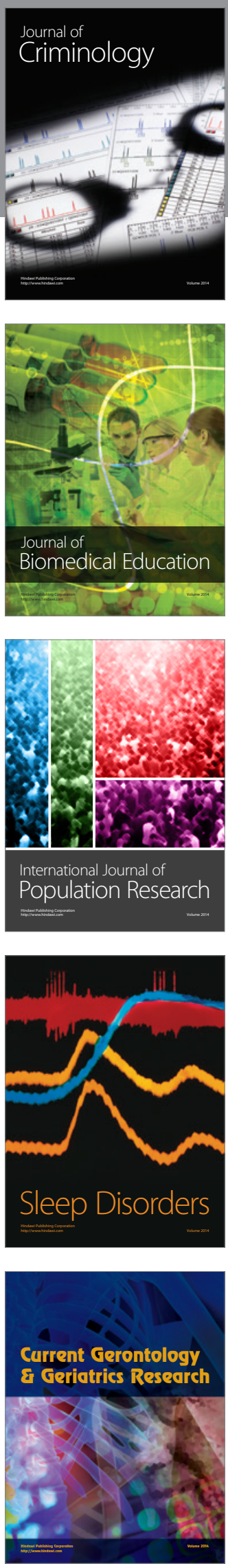
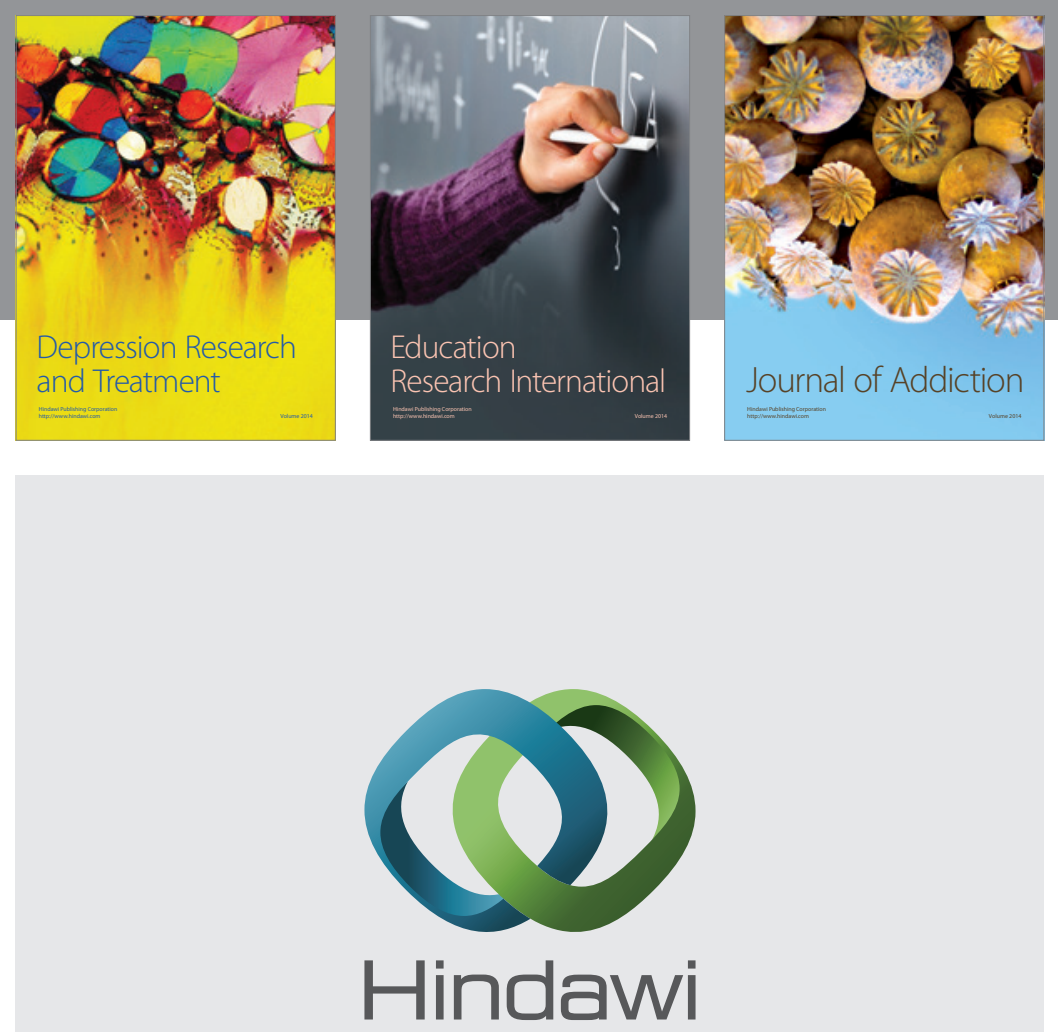

Submit your manuscripts at

http://www.hindawi.com

Child Development Research
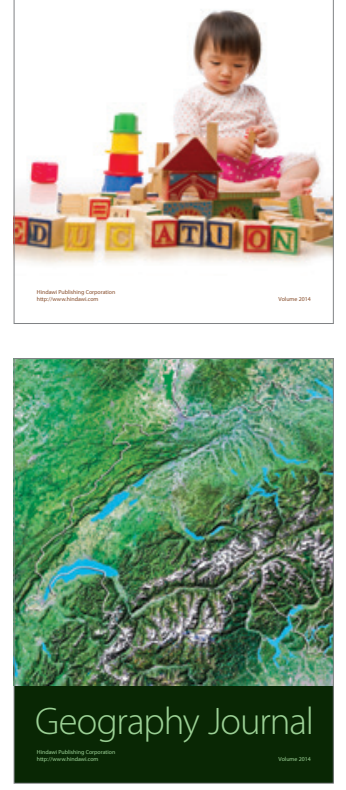

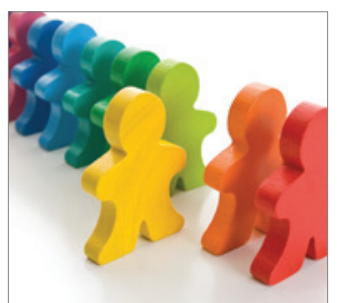

Autism

Research and Treatment
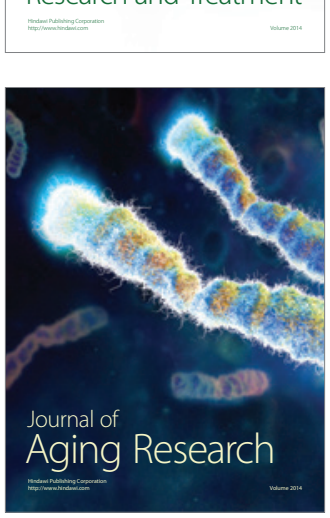
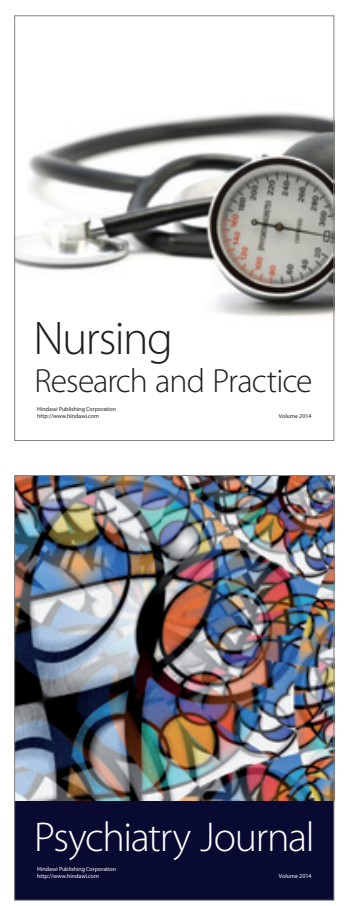
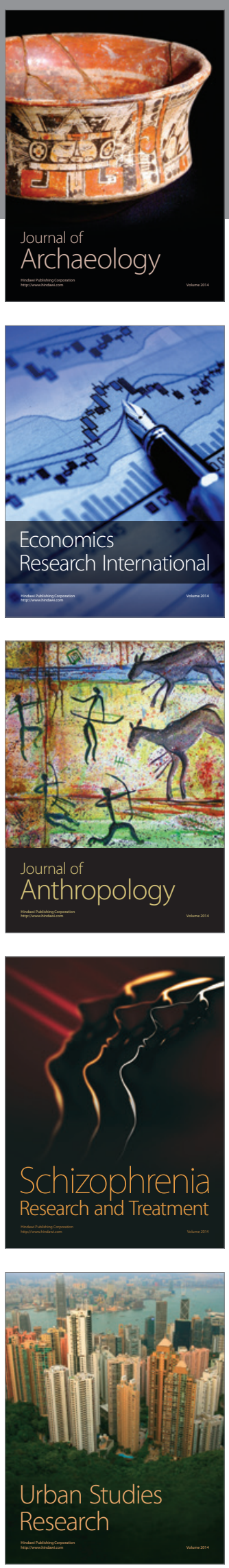